\title{
Epiretinal membrane and cystoid macular edema as predictive factors of recurrent proliferative vitreoretinopathy
}

This article was published in the following Dove Press journal:

Clinical Ophthalmology

10 October 2017

Number of times this article has been viewed

Kunyong $\mathrm{Xu}^{\mathrm{l}}$

Eric K Chin ${ }^{2}$

D Wilkin Parke $3 r^{3}$

David RP Almeida ${ }^{3}$

'Department of Ophthalmology, Weill Cornell Medicine, Cornell University, New York, NY, ${ }^{2}$ Retina Consultants of Southern California, Redlands, CA, ${ }^{3}$ VitreoRetinal Surgery, PA,

Minneapolis, MN, USA
Correspondence: David RP Almeida VitreoRetinal Surgery, PA, 7760 France Ave S., Minneapolis, MN 55435, USA

$\mathrm{Tel}+\mid 952929$ | | 3 |

Email dalmeida@evolation-medical.com
Purpose: Proliferative vitreoretinopathy (PVR) is the most common cause of recurrent retinal detachment (RD). We sought to determine the predictive factors of recurrent PVR formation and the need for additional vitreoretinal surgical intervention after uncomplicated primary RD repair.

Methods: This is a retrospective single-center case-control study of consecutive patients with PVR formation after uncomplicated RD repair. Logistic regression was used to assess factors associated with recurrent PVR formation.

Results: Thirty-seven eyes (37 patients) who had recurrent RD secondary to PVR formation were included. Among those, 27 eyes needed one additional surgery, whereas the remainder 10 eyes required two or more additional surgeries. In the univariate analysis, patients who had cystoid macular edema (CME) after the second surgery were 8.33 times (crude odds ratio [COR], 95\% confidence interval $[\mathrm{CI}]$ : $1.23-56.67, p=0.0302$ ) more likely to have recurrent PVR formation compared to those who did not have CME after the second surgery. Similarly, those who had epiretinal membrane (ERM) after the second surgery were 8.00 times (COR, 95\% CI: 1.43-44.92, $p=0.0182$ ) more likely to have recurrent PVR formation compared to those who did not have ERM after the second surgery. In the multivariate analysis, patients who had ERM after the second surgery were 8.20 times (adjusted odds ratio [AOR], 95\% CI: $1.08-62.40, p=0.0422$ ) more likely to develop recurrent PVR compared to those who did not have ERM after the second surgery, when adjusted for age, sex, and CME after the second surgery.

Conclusion: ERM and CME are potential predictive factors for recurrent PVR formation after uncomplicated primary RD repair. Early recognition and treatment of ERM and CME may be critical to prevent subsequent PVR formation and improve visual outcomes.

Keywords: epiretinal membrane, cystoid macular edema, proliferative vitreoretinopathy, retinal detachment, rhegmatogenous retinal detachment

\section{Introduction}

Proliferative vitreoretinopathy (PVR) is characterized by the formation of epiretinal and subretinal contracting membranes, and it is the most common reason for surgical failure following rhegmatogenous retinal detachment (RD). ${ }^{1,2}$ PVR formation occurs in $~ 5 \%-10 \%$ of all RDs. ${ }^{3,4}$ The pathophysiology of PVR formation involves cellular proliferation, migration, and inflammation. ${ }^{5,6}$

Our previous study suggested that cigarette smoking, RD involving the macula, and large-gauge vitrectomy are significant risk factors predictive of PVR formation after uncomplicated primary $\mathrm{RD}$ repair (Xu K et al, unpublished data, 2017). At the onset of PVR formation, some patients will have successful repair with one additional surgery; 
however, recurrent PVR requiring multiple surgeries remain some of the most challenging cases for retina surgeons today. Currently, the clinical findings associated with recurrent PVR formation represent a knowledge gap in the literature. In our study, we identify the predictive clinical findings associated with recurrent PVR formation and the need for additional vitreoretinal surgical intervention.

\section{Methods Study design}

This is a retrospective case-control study involving consecutive RD patients who required subsequent retina surgery due to postoperative recurrent RD secondary to PVR formation. Those patients were evaluated and treated at a multi-site single private practice institution (VitreoRetinal Surgery, PA, Minneapolis, MN, USA) involving nine different US-trained vitreoretinal surgeons between January 2014 and December 2015. This study adheres to the tenets of the Declaration of Helsinki, and it was approved by the Salus Institutional Review Board (Austin, TX, USA). All patients provided written consent to review their medical records.

Patient charts and operative reports were carefully reviewed. All patients had required routine preoperative and postoperative examinations. For each patient, a detailed fundus drawings were documented in the clinical and surgical notes which included the number and location of retinal tears as well as any findings of PVR. PVR was graded according to the Silicone Study Group classification. ${ }^{7}$ Specifically, PVR cases were defined as having proliferative epiretinal membrane (ERM) formation (eg, ERMs and starfolds), with or without subretinal membranes, causing diffuse contraction of the posterior retina resulting in retinal re-detachment and need for additional surgery. When ERM was identified after primary RD repair, ERM and internal limiting membrane peels were done at the time of recurrent RD repair (second surgery).

\section{Inclusion and exclusion criteria}

All patients who underwent uncomplicated RD repair without preoperative PVR formation were identified. After PVR formation, patients who needed one or more additional surgeries due to PVR formation after uncomplicated primary $\mathrm{RD}$ repair were included. Any patient with a past history of recurrent RD (repaired elsewhere), a past vitreoretinal surgery for any cause (eg, macular hole or ERM surgery), or a diagnosis of complicated RD on presentation (eg, RD with PVR at initial presentation, tractional RD, RD caused by a giant retinal tear, or $\mathrm{RD}$ secondary to trauma or penetrating injury) was excluded. Additionally, any patients with vision loss secondary to other comorbid eye conditions other than rhegmatogenous RD upon initial repair (such as glaucoma, ERM, and macular edema) were excluded. Patients who experienced an intraoperative complication during primary RD repair (eg, vitreous hemorrhage and suprachoroidal hemorrhage) were also excluded.

\section{Identification of cases and controls}

Included patients were divided into either the recurrent PVR group (PVR formation requiring two or more additional surgeries) or the control group (PVR formation was repaired with only one additional surgery). In addition to clinical examinations, intravenous fluorescein angiography and spectral domain-optical coherence tomography (SD-OCT) were used to identify the presence of CME while SD-OCT was used to detect the ERM.

\section{Potential predictive variables for recurrent PVR formation}

Preoperative variables included age, sex, cigarette smoking status, alcohol intake, preoperative best-corrected visual acuity (BCVA) via logarithm of the minimum angle of resolution (LogMAR) acuity, intraocular pressure (IOP), high myopia (defined as refractive error $\geq-6.0 \mathrm{D}),{ }^{8}$ family history of $\mathrm{RD}$, lens status (phakia versus pseudophakia), location of RTs, total number of RTs, large RT $\left(>30^{\circ}\right.$ but $\left.<90^{\circ}\right)$, RD involving macula, presence of lattice degeneration, presence of cystoid macular edema (CME), presence of ERM, presence of vitreous hemorrhage, duration of RD symptoms (eg, photopsias, floaters, or peripheral vision loss; defined as the time between initial RD symptoms and primary surgery for $\mathrm{RD}$ repair).

Intraoperative variables included surgical technique (primary scleral buckle [SB], pars plana vitrectomy [PPV], or combination of SB with vitrectomy), PPV gauge (20, 23, or 25 gauge), and tamponade agent (sulfur hexafluoride $\left[\mathrm{SF}_{6}\right]$ gas, perfluoropropane $\left[\mathrm{C}_{3} \mathrm{~F}_{8}\right]$ gas, or silicone oil [SO]).

Postoperative factors included the formation of PVR after the primary surgery, postoperative CME, postoperative ERM, total number of surgeries needed for anatomical success, follow-up time, final postoperative BCVA, and final postoperative IOP.

\section{Statistical analysis}

Descriptive analysis was used to describe the sample characteristics. Continuous variables were described in means and standard deviations (SDs). Categorical variables were 
described in frequencies and percentages (\%). To compare different groups in categorical variables, chi-square tests or Fisher's exact tests $(\mathrm{n}<5)$ were used. Student's $t$-tests were used to compare the means for different categories.

Logistic regression analysis was used to assess the potential factors associated with recurrent PVR formation after uncomplicated primary RD repair. For univariate analysis, each preoperative, intraoperative, or postoperative factor was considered separately in a model to predict the recurrent PVR formation after an uncomplicated primary RD repair. Crude odds ratio (COR) and 95\% confidence interval (CI) were obtained for each factor. Multivariate logistic regression models were used to identify the possible risk factors for recurrent PVR formation after uncomplicated primary $\mathrm{RD}$ repair. Adjusted odds ratio (AOR) and 95\% CI were obtained for each factor in the multivariate analysis. Factor with a two-tailed $p$-value $<0.05$ was considered significant. All statistical analyses were performed using the SAS, version 9.3 (SAS Institute Inc., Cary, NC, USA).

\section{Results}

Thirty-seven eyes (37 patients) that had PVR formation following uncomplicated primary surgery for $\mathrm{RD}$ repair were included. During the study period, there were 2,760 patients who had surgery for primary RD repair and all of them had a minimal 1-year follow-up after the surgery. Among those patients, 37 (1.3\%) developed PVR. As reported in our previous study, surgeon factor was not associated with PVR formation after primary RD repair (Xu K et al, unpublished data, 2017).

Among those, 27 eyes required one additional surgery, whereas 10 eyes required two or more additional surgeries. The mean age of the study sample was $63.7(\mathrm{SD}=12.1)$ years and $54.1 \%$ patients were male $(n=20)$. Overall, the mean duration of preoperative RD symptoms was 18.5 ( $\mathrm{SD}=26.1)$ days, and the mean follow-up time was 368.0 ( $\mathrm{SD}=166.8)$ days. The mean BCVA for all patients at the final follow-up was 1.0 LogMAR ( $\mathrm{SD}=0.7$ ). The mean BCVA at final follow-up was 1.3 $\operatorname{LogMAR}(\mathrm{SD}=0.7)$ for recurrent PVR group and 0.9 LogMAR ( $\mathrm{SD}=0.7$ ) for control group. The preoperative and postoperative characteristics between recurrent PVR group and control group are shown in Table 1.

Most patients had either combination of SB plus PPV $(\mathrm{n}=23,62.3 \%)$ or PPV alone $(\mathrm{n}=13,35.0 \%)$ as the primary surgery for uncomplicated $\mathrm{RD}$ repair. $\mathrm{SF}_{6}$ gas $(\mathrm{n}=23,62.2 \%)$ was the most commonly use tamponade agent in comparison with $\mathrm{C}_{3} \mathrm{~F}_{8}$ gas $(\mathrm{n}=12,32.4 \%)$ for the primary repair. 20-, 23 -, and 25-gauge vitrectomy was performed in $8(22.2 \%)$, 19 (52.8\%), and 9 (25.0\%) patients, respectively. Table 2 shows the surgical details comparing the recurrent PVR and control groups.

Table I Baseline sample characteristics $(n=37)$

\begin{tabular}{|c|c|c|c|c|}
\hline \multirow[t]{2}{*}{ Characteristics } & \multicolumn{2}{|c|}{ Control group $(n=27)$} & \multicolumn{2}{|c|}{ Recurrent PVR group $(n=\mid 0)$} \\
\hline & Mean (SD) & Frequency (\%) & Mean (SD) & Frequency (\%) \\
\hline \multicolumn{5}{|l|}{ Preoperative factors } \\
\hline Age (years) & $63.3(13.7)$ & & $64.8(6.6)$ & \\
\hline \multicolumn{5}{|l|}{ Sex } \\
\hline Male & & $16(59.3)$ & & $4(40.0)$ \\
\hline \multicolumn{5}{|l|}{ Duration of RD symptoms (days) } \\
\hline$\leq 14$ & & $15(55.6)$ & & $8(80.0)$ \\
\hline$>14$ & & $12(44.4)$ & & $2(20.0)$ \\
\hline \multicolumn{5}{|l|}{ High myopia } \\
\hline Yes & & $9(33.3)$ & & $6(60.0)$ \\
\hline No & & $18(66.7)$ & & $4(40.0)$ \\
\hline \multicolumn{5}{|l|}{ RD involving macula } \\
\hline Yes & & $17(63.0)$ & & $5(50.0)$ \\
\hline No & & $10(37.0)$ & & $5(50.0)$ \\
\hline \multicolumn{5}{|l|}{ Postoperative factors } \\
\hline BCVA (LogMAR) at the last visit & $0.9(0.7)$ & & $\mathrm{I} .3(0.7)$ & \\
\hline$>0.4$ & & $5(18.5)$ & & $0(0.0)$ \\
\hline$\leq 0.4$ & & $22(81.5)$ & & $10(100.0)$ \\
\hline Final IOP (mmHg) & I5.I (3.9) & & | $4.3(8.9)$ & \\
\hline Follow-up (days) & $386.3(170.1)$ & & $318.5(154.8)$ & \\
\hline \multicolumn{5}{|c|}{ Successful anatomical repair at the last visit } \\
\hline Yes & & $100(100)$ & & $100(100)$ \\
\hline No & & $0(0.0)$ & & $0(0.0)$ \\
\hline
\end{tabular}

Abbreviations: SD, standard deviation; PVR, proliferative vitreoretinopahty; RD, retinal detachment; BCVA, best-corrected visual acuity; IOP, intraocular pressure. 
Table 2 Surgical details for the primary and the secondary surgeries for recurrent PVR and control groups

\begin{tabular}{|c|c|c|c|c|}
\hline \multirow[t]{2}{*}{ Details } & \multicolumn{2}{|l|}{ Control group $(n=27)$} & \multicolumn{2}{|c|}{ Recurrent PVR group $(n=10)$} \\
\hline & Primary surgery, n (\%) & Secondary surgery, n (\%) & Primary surgery, n (\%) & Secondary surgery, n (\%) \\
\hline \multicolumn{5}{|l|}{ Surgical technique } \\
\hline Scleral buckle & I (3.7) & $0(0.0)$ & $0(0.0)$ & $0(0.0)$ \\
\hline Pars plana vitrectomy & $8(29.6)$ & $16(59.3)$ & $5(50.0)$ & $6(60.0)$ \\
\hline $\begin{array}{l}\text { Scleral buckle plus pars } \\
\text { plana vitrectomy }\end{array}$ & $18(66.7)$ & II (40.7) & $5(50.0)$ & $4(40.0)$ \\
\hline \multicolumn{5}{|l|}{ Tamponade agent } \\
\hline Sulfur hexafluoride $\left(\mathrm{SF}_{6}\right)$ & $17(63.0)$ & $4(14.8)$ & $6(60.0)$ & $0(0.0)$ \\
\hline Octafluoropropane $\left(\mathrm{C}_{3} \mathrm{~F}_{8}\right)$ & $8(29.6)$ & $5(18.5)$ & $4(40.0)$ & $4(40.0)$ \\
\hline Silicon oil & $2(7.4)$ & $18(66.7)$ & $0(0.0)$ & $6(60.0)$ \\
\hline \multicolumn{5}{|l|}{ Pars plana vitrectomy gauge (g) } \\
\hline 20 & $6(22.2)$ & $5(18.5)$ & $2(20.0)$ & I (I0.0) \\
\hline 23 & 14 (5।.9) & $18(66.7)$ & $6(60.0)$ & $7(70.0)$ \\
\hline 25 & $7(25.9)$ & $4(14.8)$ & $2(20.0)$ & $2(20.0)$ \\
\hline
\end{tabular}

Abbreviation: PVR, proliferative vitreoretinopathy.

There was no difference in the percentage of postoperative CME and postoperative ERM after the primary surgery for uncomplicated RD repair between recurrent PVR group and control group (Table 3). However, a significant higher percentage of patients had CME and ERM after the second surgery in the recurrent PVR group compared to control group (Table 3).

In the univariate analysis (Table 4), patients who had CME after the second surgery were 8.33 times (COR, 95\% CI: $1.23-56.67, p=0.0302$ ) more likely to have recurrent PVR formation compared to those who did not have CME after the second surgery. Similarly, those who had ERM after the second surgery were 8.00 times (COR, 95\% CI: 1.43-44.92, $p=0.0182$ ) more likely to have recurrent PVR formation compared to those who did not have ERM after the second surgery. Preoperative and intraoperative factors were not found to be associated with recurrent PVR formation (Table 4). In the multivariate analysis (Table 5), patients who had ERM after the second surgery were 8.20 times (AOR, 95\% CI: $1.08-62.40, p=0.0422)$ more likely to develop recurrent PVR compared to those who did not have ERM after the second surgery, when adjusted for age, sex, and CME after the second surgery.

\section{Discussion}

PVR represents an anomalous scarring process after surgery due to inflammation and cellular proliferation. It is a frequent complication of $\mathrm{RD}$ and vitreoretinal surgery, causing the formation of preretinal avascular fibrocellular membranes. ${ }^{9}$ Despite the evolution of vitreoretinal surgical techniques, the frequency of PVR remained largely unchanged. ${ }^{10}$ In our study, we found that the presence of ERM and CME might be predictive of recurrent PVR formation after uncomplicated primary RD repair.

ERMs consist of various cell types including retinal pigment epithelial cells, fibroblasts, glial cells, and vascular endothelial cells; however, the exact mechanism for ERM formation is not clear. ${ }^{11}$ ERMs have been reported to be associated with PVR. ${ }^{12}$ Studies showed that ERMs formed after surgery for complicated RD with PVR. ${ }^{13,14}$ It was suggested that there was a significant association between clinical grades of PVR and the expression levels of specific

Table 3 Complications after the primary and the secondary surgeries

\begin{tabular}{|c|c|c|c|c|c|c|}
\hline \multirow{2}{*}{$\begin{array}{l}\text { Postoperative } \\
\text { complications }\end{array}$} & \multicolumn{2}{|c|}{ Postprimary surgery } & \multirow[t]{2}{*}{$p$-value } & \multicolumn{2}{|c|}{ Postsecondary surgery } & \multirow[t]{2}{*}{$p$-value } \\
\hline & $\begin{array}{l}\text { Control } \\
\text { group, n (\%) }\end{array}$ & $\begin{array}{l}\text { Recurrent PVR } \\
\text { group, n (\%) }\end{array}$ & & $\begin{array}{l}\text { Control } \\
\text { group, n (\%) }\end{array}$ & $\begin{array}{l}\text { Recurrent PVR } \\
\text { group, n (\%) }\end{array}$ & \\
\hline Cystic macular edema & I (3.7) & $3(30.0)$ & 0.0522 & $2(7.4)$ & $4(40.0)$ & 0.0347 \\
\hline High intraocular pressure & $0(0.0)$ & I (I0.0) & 0.2703 & $0(0.0)$ & $0(0.0)$ & \\
\hline Hypotony & $0(0.0)$ & $0(0.0)$ & & $0(0.0)$ & $0(0.0)$ & \\
\hline Vitreous hemorrhage & $0(0.0)$ & $0(0.0)$ & & I (3.7) & $0(0.0)$ & 0.7297 \\
\hline Keratopathy & $0(0.0)$ & $0(0.0)$ & & $0(0.0)$ & $0(0.0)$ & \\
\hline Epiretinal membrane & $10(37.0)$ & $2(20.0)$ & 0.4447 & $3(\mathrm{II} . \mathrm{I})$ & $5(50.0)$ & 0.0191 \\
\hline
\end{tabular}

Abbreviation: PVR, proliferative vitreoretinopathy. 
Table 4 Univariate analysis: factors associated with recurrent PVR formation after the primary surgery for retinal detachment repair $(n=37)$

\begin{tabular}{|c|c|c|}
\hline Variables & COR & $p$-value \\
\hline \multicolumn{3}{|l|}{ Preoperative factors } \\
\hline \multicolumn{3}{|l|}{ Age (years) } \\
\hline$>55$ & $2.05(0.2 \mathrm{I}, 20.05)$ & 0.5389 \\
\hline$\leq 55$ & 1.00 & \\
\hline \multicolumn{3}{|l|}{ Sex } \\
\hline Female & $2.18(0.50,9.58)$ & 0.3015 \\
\hline Male & 1.00 & \\
\hline \multicolumn{3}{|l|}{ Cigarette smoking status } \\
\hline Previous or current & $2.51(0.53,11.83)$ & 0.2436 \\
\hline Never & 1.00 & \\
\hline \multicolumn{3}{|l|}{ Alcohol intake status } \\
\hline Previous or current alcohol intake & $1.03(0.24,4.53)$ & 0.9695 \\
\hline Never & 1.00 & \\
\hline \multicolumn{3}{|l|}{ Duration of RD symptoms (days) } \\
\hline$>14$ & $3.20(0.57,17.97)$ & 0.1864 \\
\hline$\leq 14$ & 1.00 & \\
\hline \multicolumn{3}{|l|}{ High myopia } \\
\hline Yes & $3.00(0.67,13.40)$ & 0.1503 \\
\hline No & 1.00 & \\
\hline \multicolumn{3}{|l|}{ RD involving macula } \\
\hline Yes & $0.59(0.14,2.55)$ & 0.4778 \\
\hline No & 1.00 & \\
\hline \multicolumn{3}{|l|}{ Location of retinal break(s) } \\
\hline Inferior $180^{\circ} \pm$ superior $180^{\circ}$ & $0.73(0.15,3.47)$ & 0.6911 \\
\hline Superior $180^{\circ}$ & 1.00 & \\
\hline \multicolumn{3}{|l|}{ Number of retinal break(s) } \\
\hline 1 & $2.35(0.42,13.34)$ & 0.3338 \\
\hline$\geq 2$ & 1.00 & \\
\hline \multicolumn{3}{|l|}{ Lens status } \\
\hline Phakic & $1.25(0.29,5.35)$ & 0.7635 \\
\hline Pseudophakic & 1.00 & \\
\hline \multicolumn{3}{|l|}{ Lattice degeneration of operated eye } \\
\hline Yes & $3.79(0.4 \mathrm{I}, 35.05)$ & 0.2406 \\
\hline No & 1.00 & \\
\hline \multicolumn{3}{|l|}{ Lattice degeneration of contralateral eye } \\
\hline Yes & $2.05(0.2 I, 20.05)$ & 0.5389 \\
\hline No & 1.00 & \\
\hline \multicolumn{3}{|l|}{ Large tear } \\
\hline Yes & $3.13(0.38,25.92)$ & 0.2911 \\
\hline No & 1.00 & \\
\hline \multicolumn{3}{|l|}{ Vitreous hemorrhage } \\
\hline Yes & $5.35(0.74,38.64)$ & 0.0959 \\
\hline No & 1.00 & \\
\hline \multicolumn{3}{|l|}{ BCVA (LogMAR) } \\
\hline$>0.4$ & $1.20(0.27,5.25)$ & 0.8086 \\
\hline$\leq 0.4$ & 1.00 & \\
\hline \multicolumn{3}{|l|}{ IOP $(\mathrm{mmHg})$} \\
\hline$>15$ & $1.58(0.35,7.17)$ & 0.5511 \\
\hline$\leq 15$ & 1.00 & \\
\hline \multicolumn{3}{|l|}{ Intraoperative factors } \\
\hline \multicolumn{3}{|l|}{ Surgical technique } \\
\hline Pars plana vitrectomy & $2.38(0.54,10.53)$ & 0.2551 \\
\hline Scleral buckle \pm pars plana vitrectomy & 1.00 & \\
\hline
\end{tabular}

(Continued)
Table 4 (Continued)

\begin{tabular}{lll}
\hline Variables & COR & p-value \\
\hline $\begin{array}{l}\text { Tamponade agent } \\
\quad \text { Octafluoropropane }\left(\mathrm{C}_{3} \mathrm{~F}_{8}\right)\end{array}$ & $\mathrm{n} / \mathrm{a}$ & $\mathrm{n} / \mathrm{a}$ \\
$\quad \begin{array}{l}\text { Sulfur hexafluoride }\left(\mathrm{SF}_{6}\right) \\
\text { Pars plana vitrectomy gauge }(\mathrm{g})\end{array}$ & & \\
$\quad 20$ or 23 & $1.40(0.24,8.24)$ & 0.7099 \\
25 & 1.00 & \\
$\begin{array}{l}\text { Postprimary surgery } \\
\text { Cystic macular edema }\end{array}$ & & \\
$\quad$ Yes & $1.89(0.36,9.97)$ & $0.455 \mathrm{I}$ \\
$\quad$ No & 1.00 & \\
Epiretinal membrane & & \\
$\quad$ Yes & $2.35(0.42,13.34)$ & 0.3338 \\
$\quad$ No & 1.00 & \\
$\begin{array}{l}\text { Postsecondary surgery } \\
\text { Cystic macular edema }\end{array}$ & & \\
$\quad$ Yes & $8.33(1.23,56.67)$ & 0.0302 \\
$\quad$ No & 1.00 & \\
Epiretinal membrane & & \\
Yes & $8.00(1.43,44.92)$ & 0.0182 \\
No & 1.00 & \\
\hline
\end{tabular}

Abbreviations: PVR, proliferative vitreoretinopathy; COR, crude odds ratio; RD, retinal detachment.

cytokines and/or growth factors in the vitreous fluid. ${ }^{11}$ Interestingly, expression of these factors and their receptors are also found in ERMs. ${ }^{11}$ In our study, we found that the development of ERMs was associated with recurrent PVR formation. This might suggest that ERM is a surrogate for uncontrolled underlying PVR. In our opinion, early ERM formation in the context of a history of PVR might suggest careful consideration for removal because this is associated with a high rate of progression to PVR development. We postulate that ERM formation in the context of PVR might be due to an increase in cytokines and growth factors

Table 5 Multivariate analysis: factors associated with recurrent PVR formation after the primary surgery for retinal detachment repair $(n=37)$

\begin{tabular}{|c|c|c|}
\hline Variables & AOR & $p$-value \\
\hline \multicolumn{3}{|c|}{ Preoperative factors } \\
\hline \multicolumn{3}{|l|}{ Age (years) } \\
\hline$>55$ & $2.58(0.16,41.96)$ & 0.0506 \\
\hline$\leq 55$ & 1.00 & \\
\hline \multicolumn{3}{|l|}{ Sex } \\
\hline Female & $2.74(0.42,17.73)$ & 0.2905 \\
\hline Male & 1.00 & \\
\hline \multicolumn{3}{|c|}{ Postsecondary surgery } \\
\hline \multicolumn{3}{|c|}{ Cystic macular edema } \\
\hline Yes & $5.13(0.59,44.40)$ & 0.1372 \\
\hline No & 1.00 & \\
\hline \multicolumn{3}{|c|}{ Epiretinal membrane } \\
\hline Yes & $8.20(1.08,62.40)$ & 0.0422 \\
\hline No & 1.00 & \\
\hline
\end{tabular}


that continue to drive PVR formation, retinal foreshortening, and subsequent RD.

CME frequently develops as a result of blood-retinal barrier dysfunction. ${ }^{15}$ It has been suggested that inflammatory mediators probably initiate the development of inflammatory macular edema, but the exact factors and events responsible for further CME development have not yet been identified. ${ }^{16}$ Kiss et al showed that CME can occur after SO removal for complicated RD with PVR repair. ${ }^{13}$ Similarly, CME was also reported after PPV and gas tamponade for rhegmatogenous RD complicated by PVR. ${ }^{14}$ In our study, the development of postoperative CME was associated with recurrent PVR formation in the univariate analysis. This might indicate that CME could be an early sign for PVR formation after uncomplicated primary RD repair. However, this association was not found in the multivariate analysis, which might be due to the small sample size and associated low statistical power.

CME in cases of PVR can be difficult to treat. From our data, we can surmise that CME following recurrent PVR likely represents a derangement of inflammatory mediators that accelerate the progression of PVR formation and increase rates of $\mathrm{RD}$. In both the cases of ERM and CME formation in PVR, we can see that these may be aberrant processes linked to local inflammatory disruption and should be considered for early and aggressive treatment.

Our study has some limitations, including its retrospective nature and small sample size. Studies with larger sample sizes are necessary to further assess the predictive factors for recurrent PVR formation in the context of uncomplicated primary $\mathrm{RD}$ repair. In addition, basic science research will be important and helpful to unveil the association between ERM, CME, and PVR formation among patients with uncomplicated primary $\mathrm{RD}$ repair.

\section{Conclusion}

To our knowledge, this is the first study to assess the predictive factors for recurrent PVR formation after uncomplicated primary RD repair. In this study, we identify ERM and CME as potential predictive factors for recurrent PVR formation after uncomplicated primary RD repair. This suggests that early recognition and treatment of ERM and CME might be important to prevent PVR formation and to achieve better visual outcome for those who undergo uncomplicated primary $\mathrm{RD}$ repair.

\section{Disclosure}

The authors report no conflicts of interest in this work.

\section{References}

1. Ryan SJ. The pathophysiology of proliferative vitreoretinopathy and its management. Am J Ophthalmol. 1985;100:188-193.

2. Ryan SJ. Traction retinal detachment. XLIX Edward Jackson Memorial Lecture. Am J Ophthalmol. 1993;115:1-20.

3. Cardillo JA, Stout JT, LaBree L, et al. Post-traumatic proliferative vitreoretinopathy. The epidemiologic profile, onset, risk factors, and visual outcome. Ophthalmology. 1997;104:1166-1173.

4. Pastor JC. Proliferative vitreoretinopathy: an overview. Surv Ophthalmol. 1998;43:3-18.

5. Campochiaro PA. Pathogenic mechanisms in proliferative vitreoretinopathy. Arch Ophthalmol. 1997;115:237-241.

6. Limb GA, Little BC, Meager A, et al. Cytokines in proliferative vitreoretinopathy. Eye (Lond). 1991;5:686-693.

7. Lean JS, Stern WH, Irvine AR, Azen SP; Silicone Study Group. Classification of proliferative vitreoretinopathy used in the silicone study. Ophthalmology. 1989;96:765-771.

8. Wong TY, Foster PJ, Johnson GJ, Seah SK. Refractive errors, axial ocular dimensions, and age-related cataracts: the Tanjong Pagar survey. Invest Ophthalmol Vis Sci. 2003;44:1479-1485.

9. Bringmann A, Wiedemann P. Involvement of Müller glial cells in epiretinal membrane formation. Graefes Arch Clin Exp Ophthalmol. 2009; 247:865-883.

10. Charteris DG, Sethi CS, Lewis GP, Fisher SK. Proliferative vitreoretinopathy-developments in adjunctive treatment and retinal pathology. Eye. 2002;16:369-374.

11. Harada C, Mitamura Y, Harada T. The role of cytokines and trophic factors in epiretinal membranes: involvement of signal transduction in glial cells. Prog Retin Eye Res. 2006;25:149-164.

12. Hiscott $\mathrm{P}$, Wong D, Grierson I. Challenges in ophthalmic pathology: the vitreoretinal membrane biopsy. Eye. 2000;14:549-559.

13. Kiss CG, Richter-Müksch S, Sacu S, Benesch T, Velikay-Parel M. Anatomy and function of the macula after surgery for retinal detachment complicated by proliferative vitreoretinopathy. Am J Ophthalmol. 2007;144:872-877.

14. Bonnet M. Macular changes and fluorescein angiographic findings after repair of proliferative vitreoretinopathy. Retina. 1994;14:404-410.

15. Choi JY, Buzney SM, Weiter JJ. Cystoid macular edema: current modes of therapy. Int Ophthalmol Clin. 2005;45:143-151.

16. Rothova A. Inflammatory cystoid macular edema. Curr Opin Ophthalmol. 2007;18:487-492.
Clinical Ophthalmology

\section{Publish your work in this journal}

Clinical Ophthalmology is an international, peer-reviewed journal covering all subspecialties within ophthalmology. Key topics include: Optometry; Visual science; Pharmacology and drug therapy in eye diseases; Basic Sciences; Primary and Secondary eye care; Patient Safety and Quality of Care Improvements. This journal is indexed on Submit your manuscript here: http://www.dovepress.com/clinical-ophthalmology-journal

\section{Dovepress}

PubMed Central and CAS, and is the official journal of The Society of Clinical Ophthalmology (SCO). The manuscript management system is completely online and includes a very quick and fair peer-review system, which is all easy to use. Visit http://www.dovepress.com/ testimonials.php to read real quotes from published authors. 